\title{
Structural Conformational Study of Eugenol Derivatives Using Semiempirical Methods
}

\author{
Radia Mahboub \\ Department of Chemistry, Faculty of Sciences, University of Tlemcen, BP 119, 13000 Tlemcen, Algeria \\ Correspondence should be addressed to Radia Mahboub; radiamahboub@yahoo.com
}

Received 3 June 2014; Accepted 29 September 2014; Published 20 October 2014

Academic Editor: Maria Roca

Copyright ( 2014 Radia Mahboub. This is an open access article distributed under the Creative Commons Attribution License, which permits unrestricted use, distribution, and reproduction in any medium, provided the original work is properly cited.

\begin{abstract}
We investigated the conformational structure of eugenol and eugenyl acetate under torsional angle effect by performing semiempirical calculations using AM1 and PM3 methods. From these calculations, we have evaluated the strain energy of conformational interconversion. To provide a better estimate of stable conformations, we have plotted the strain energy versus dihedral angle. So, we have determined five geometries of eugenol (three energy minima and two transition states) and three geometries of eugenyl acetate (two energy minima and one transition state). From the molecular orbital calculations, we deduce that the optimized trans form by AM1 method is more reactive than under PM3 method. We can conclude that both methods are efficient. The AM1 method allows us to determine the reactivity and PM3 method to verify the stability.
\end{abstract}

\section{Introduction}

Eugenol (4-allyl-2-methoxyphenol) is a phenylpropene, an allyl chain-substituted guaiacol. It is the main phenolic compound extracted from certain essential oils especially from clove oil, nutmeg, cinnamon, basil, and bay leaf [114]. Eugenol is a phenol derivative used in many areas such as perfumes, flavorings agent, and dental materials. It is used as an antiseptic, analgesic, fungicide, bactericide, insecticide, anticarcinogenic, antiallergic, antioxidant, antiinflammatory, and so forth [15-17]. As derivative, the eugenyl acetate was characterized and its structural properties have investigated by Dos Santos et al. [18, 19].

To our knowledge, a study of the conformational structure as a function of the dihedral angle was not reported. In the present paper, we investigated the conformational structure of eugenol and eugenyl acetate under torsional angle effect by performing semiempirical calculations using AM1 and PM3 methods. From these calculations, we have evaluated the strain energy of conformational interconversion to provide a better estimate of stable conformations. These results can be used to make future applications possible (Figure 1).

\section{Methodology}

Molecular modeling of the optimized eugenol and eugenyl acetate was carried out with the use of an efficient program for molecular mechanics (MM). Calculations are performed for all optimized geometries using AM1 and PM3 methods. The main molecular properties to characterize the geometry structures and the molecular orbital of the eugenyl acetate were calculated and compared. For each method, the geometry of the compound was optimized by using the Polak-Ribiere conjugate gradient algorithm with a gradient of $0.01 \mathrm{Kcal} / \mathrm{mol}$ (RMS). The following quantum chemical results are considered: heat of formation $\left(\Delta H_{f}\right)$, total energy $\left(E_{t}\right)$, minimum energy of conformation $\left(E_{\text {min,conf }}\right)$, strain energy of conformational interconversion $\left(E_{s}\right)$, energy of highest occupied molecular orbital (HOMO), energy of lowest unoccupied molecular orbital (LUMO), and HOMOLUMO energy gaps (EG).

\section{Results and Discussion}

Molecular geometries of eugenol and eugenyl acetate were optimized by semiempirical molecular orbital method (AM1 
TABLE 1: Main calculated properties of eugenol and eugenyl acetate with semiempirical methods.

\begin{tabular}{|c|c|c|c|c|c|c|c|c|c|}
\hline \multirow{3}{*}{ Entry } & \multicolumn{9}{|c|}{ Eugenol } \\
\hline & \multirow{2}{*}{ Properties } & \multicolumn{4}{|c|}{ AM1 } & \multicolumn{4}{|c|}{ PM3 } \\
\hline & & Trans & Eclipsed & Gauche & Cis & Trans & Eclipsed & Gauche & Cis \\
\hline 1 & $\Delta H_{f}$ & -43.562 & -45.560 & -45.540 & -38.360 & -44.474 & -45.230 & -45.214 & -40.236 \\
\hline 2 & $E_{t}$ & -48090.984 & -48092.980 & -48092.960 & -48085.781 & -45111.215 & -45111.973 & -45111.957 & -45106.976 \\
\hline 3 & $E_{\text {min,conf }}$ & -2496.805 & -2498.802 & -2498.782 & -2491.602 & -2497.716 & -2498.472 & -2498.456 & -2493.478 \\
\hline 4 & $E_{s}$ & 5.202 & 7.200 & 7.180 & 0.000 & 4.238 & 4.994 & 4.978 & 0.000 \\
\hline 5 & HOMO & -8.599 & -8.614 & -8.606 & -8.592 & -8.670 & -8.703 & -8.701 & -8.666 \\
\hline 6 & LUMO & 0.327 & 0.332 & 0.342 & 0.338 & 0.254 & 0.250 & 0.260 & 0.263 \\
\hline 7 & EG & 8.926 & 8.946 & 8.948 & 8.930 & 8.924 & 8.953 & 8.961 & 8.929 \\
\hline \multirow{3}{*}{ Entry } & \multicolumn{9}{|c|}{ Eugenyl acetate } \\
\hline & $s$ & \multicolumn{4}{|c|}{ AM1 } & \multicolumn{4}{|c|}{ PM3 } \\
\hline & 10pertics & Trans & Eclipsed & Gauche & Cis & Trans & Eclipsed & Gauche & Cis \\
\hline 8 & $\Delta H_{f}$ & -68.176 & -77.344 & -77.356 & -77.356 & -77.728 & -83.323 & -83.330 & -83.328 \\
\hline 9 & $E_{t}$ & -62008.605 & -62017.772 & -62017.785 & -62017.785 & -58055.633 & -58061.226 & -58061.234 & -58061.230 \\
\hline 10 & $E_{\text {min,conf }}$ & -3026.961 & -3036.129 & -3036.140 & -3036.140 & -3036.514 & -3042.108 & -3042.115 & -3042.113 \\
\hline 11 & $E_{s}$ & 9.180 & 0.012 & 0.000 & 0.000 & 5.600 & 0.005 & -0.002 & 0.000 \\
\hline 12 & HOMO & -8.852 & -9.215 & -9.205 & -9.205 & -8.925 & -9.302 & -9.297 & -9.299 \\
\hline 13 & LUMO & 0.001 & -0.134 & -0.130 & -0.130 & -0.044 & -0.191 & -0.188 & -0.189 \\
\hline 14 & $\mathrm{EG}$ & 8.852 & 9.081 & 9.075 & 9.075 & 8.881 & 9.101 & 9.109 & 9.110 \\
\hline
\end{tabular}

The strain energy $\left(E_{s}\right)$ for each geometry of a molecule is defined as the difference between the minimum energy of conformation for that geometry and the most stable conformation of the molecule.

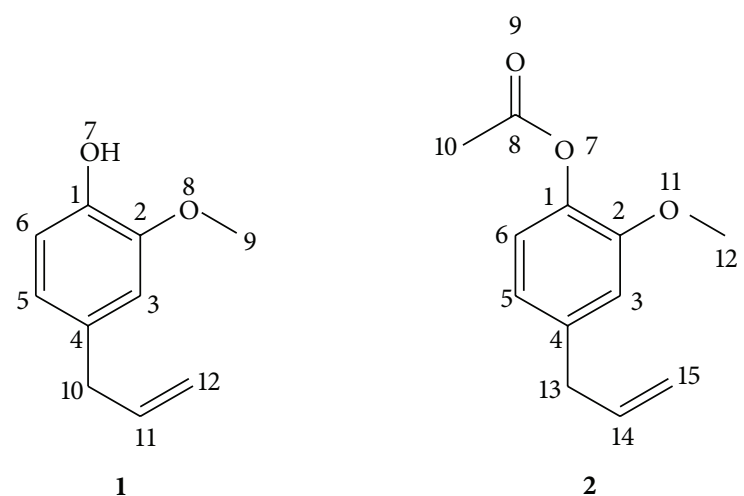

FIGURE 1: Conformation structures of cis-eugenol and cis-eugenyl acetate.

and PM3). The semiempirical simulations results for structure optimization of eugenol and eugenyl acetate are given in Table 1. The conformational interconversion energyminimum of eugenyl acetate and eugenol was investigated in detail by changing different torsional angles. From these studies, we have determined five geometries of eugenol (three energy minima and two transition states) and three geometries of eugenyl acetate (two energy minima and one transition state). These geometries are important in the description of the conformational properties of our systems (Figure 2).

We have obtained the curves plotted in Figure 2 from the simulated data using the nonlinear fitting process based on the Levenberg-Marquardt algorithm implemented in the Origin v. 6.0. Software [20].
The dihedral angle for rotation about $\mathrm{C}_{4}-\mathrm{C}_{10}$ bond in eugenol has several stationary points. $\mathrm{A} / \mathrm{A}^{\prime}, \mathrm{C}, \mathrm{C}^{\prime}$, and $\mathrm{E} / \mathrm{E}^{\prime}$ are minima and $\mathrm{B}, \mathrm{B}^{\prime}$ and $\mathrm{D}, \mathrm{D}^{\prime}$ are maxima. Only the structures at the minima represent stable species and of these, the syn conformation is more stable than the anti. The gauche and the eclipsed represent the transition states. In eugenyl acetate, the stationary points $\mathrm{A} / \mathrm{A}^{\prime}, \mathrm{B} / \mathrm{B}^{\prime}, \mathrm{C} / \mathrm{C}^{\prime}$, $\mathrm{E} / \mathrm{E}^{\prime}, \mathrm{F} / \mathrm{F}^{\prime}$, and $\mathrm{G} / \mathrm{G}^{\prime}$ are minima and $\mathrm{D}, \mathrm{D}^{\prime}$ are maxima. The anti conformation represents the transition state while the syn, gauche, and eclipsed conformations are stable species. So, the deformation around $\mathrm{C}_{4}-\mathrm{C}_{13}$ in eugenyl acetate remains unchanged and is not influenced by torsional angle effect.

To provide a better estimate of conformations, we should search the conformational space in reasonable computing time. So, we run the simulations; then we run a geometry optimization on each structure. Thus, we have grouped the resulting structures in Figure 3. First, we observe that all geometries from cis conformations obtained after optimization present deformation mainly on branching allyl. The torsional angle value varies around $136^{\circ}$. This situation is due to methylene group ( $\mathrm{sp}^{3}$ hybridization) which gives a noncoplanar final geometry. Then, the $\pi$-bond of branching allyl is situated in the same side that acetate group. Second, we note that the geometry in anti conformations stays unchanged after optimization. All the substituents of aromatic ring, acetate and methoxy groups then branching allyl, are situated in the same plane (Фtrans: $180^{\circ}$ ).

From our molecular orbital calculations, we want to deduce the structure-reactivity relationship depending on different conformations. First, AM1 and PM3 calculations show that the cis forms are favored (Table 1, entry 7, EG: 9.075, $9.110 \mathrm{ev})$. On the other hand, the same calculations show that 


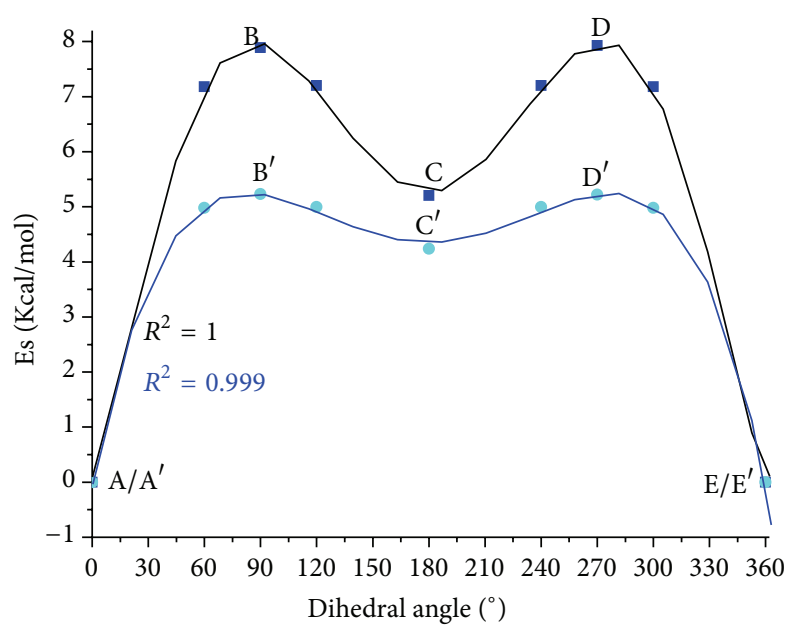

- Es1, AM1

- Es1, PM3

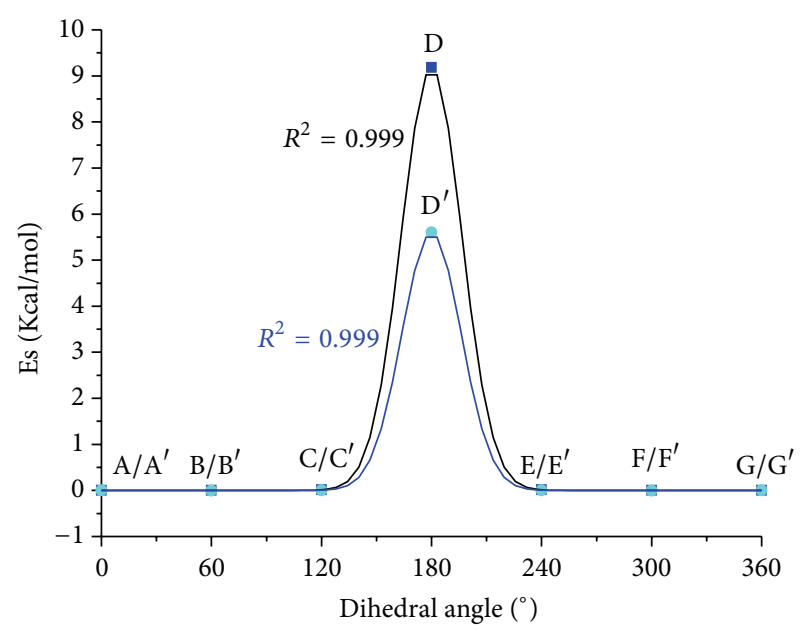

- ES, AM1

- ES, PM3

(a)

(b)

FIGURE 2: Calculated strain energy for conformational interconversion with semiempirical AM1 and PM3 methods. (a) Eugenol and (b) eugenyl acetate.

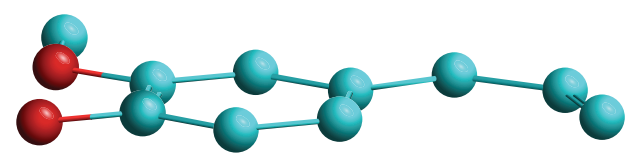

(a1)

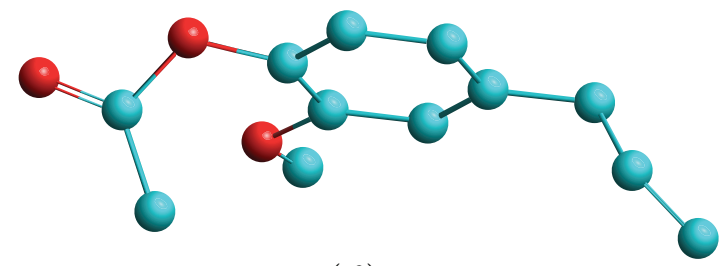

(a2)

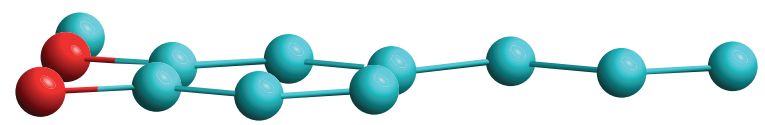

(b1)

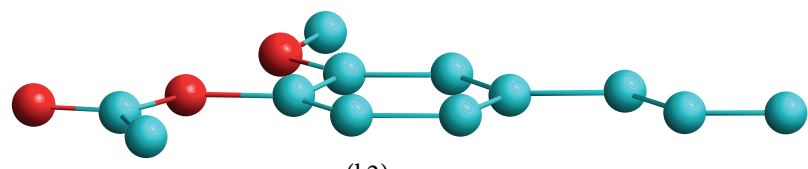

(b2)

FIGURE 3: Estimated conformation structures of eugenol and eugenyl acetate; (a1) and (a2) cis forms, (b1) and (b2) trans forms. Molecule orientation was chosen around $x$-axis. Hydrogen atoms are omitted for clarity.

the most active site of the nucleophilic reaction is located on the oxygens of the acetate group and methoxy, and the most active site of the electrophilic reaction is C8 position of eugenyl acetate.

The AM1 and PM3 calculations show that the trans form is most active (Table 1, entry 7, EG: 8.852; $8.881 \mathrm{ev}$ ). Thus, these results reveal that the instability is caused by the high activity of methylene group in the strand allyl which provides to the aromatic ring another nucleophilic reaction site. This one is stabilized by resonance with the double bonds of the aromatic ring and the allylic radical (Figure 4). So, we note that the value of the strain energy obtained with AM1 method (Table 1, entry 4, Es: $9.180 \mathrm{ev})$ is higher than that obtained by PM3

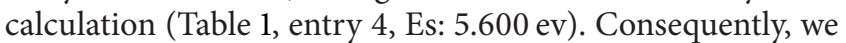
deduce that the optimized trans form by AM1 method is more reactive than under PM3 method. We can conclude that the efficient method for the eugenyl acetate is the semiempirical method AM1.

These observations remain the same for eugenol, except for the energy gaps. From Figure 2(a), we note that the trans form $\left(\mathrm{C}\right.$ or $\left.\mathrm{C}^{\prime}\right)$ is near the transition states $\mathrm{B}$ and $\mathrm{D}$, respectively, $\mathrm{B}^{\prime}$ and $\mathrm{D}^{\prime}$. This situation is clearer when the eugenol is optimized by PM3 (Table 1, entries 5 and 6 , PM3: HOMO -8.599, LUMO 0.327 ev; AM1: HOMO -8.670, LUMO $0.254 \mathrm{ev})$. So, this trans form $\left(\mathrm{C}\right.$ or $\left.\mathrm{C}^{\prime}\right)$ corresponds to the reaction intermediate present in eugenol and absent in eugenyl acetate (AM1: HOMO -8.606, LUMO 0.343; PM3: HOMO -8.702, LUMO $0.260 \mathrm{ev}$ ).

Furthermore, we also see that the HOMO is located at the oxygen sites whereas for the molecule the Homo is 


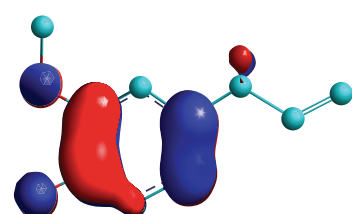

Transition state:

(a1) HOMO

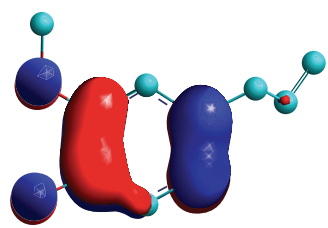

Intermediate state:

(a3) HOMO

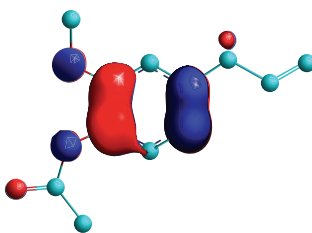

(b1) HOMO

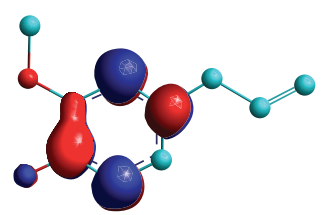

(a2) LUMO

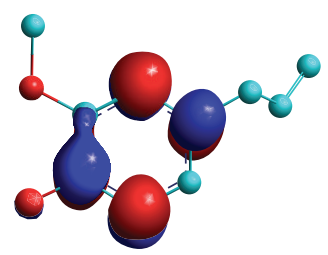

(a4) LUMO

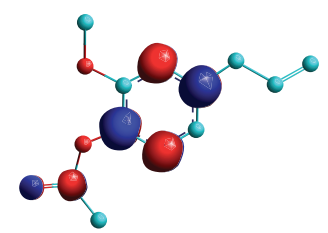

(b2) LUMO

FIGURE 4: Molecular orbital calculated for eugenol and eugenyl acetate by semiempirical methods (AM1 and PM3). Contour values: $0.05 \AA^{-3}$. Blue lines represent positive contours. Red lines represent negative contours. Hydrogen atoms are omitted for clarity.

TABLE 2: Mulliken charges of the optimized structures of eugenol and eugenyl acetate.

\begin{tabular}{|c|c|c|c|}
\hline Compound & State & Method & Type charge \\
\hline \multirow{4}{*}{ Eugenol } & \multirow{2}{*}{ Transition } & AM1 & $\begin{array}{c}\mathrm{C}_{1} 0.065, \mathrm{C}_{2} 0.058, \mathrm{C}_{3}-0.148, \mathrm{C}_{4}-0.078, \mathrm{C}_{5}-0.103, \mathrm{C}_{6}-0.165, \mathrm{O}_{7}-0.208, \mathrm{O}_{8}-0.166, \\
\mathrm{C}_{9} 0.047, \mathrm{C}_{10}-0.019, \mathrm{C}_{11}-0.134, \mathrm{C}_{12}-0.168 .\end{array}$ \\
\hline & & PM3 & $\begin{array}{c}\mathrm{C}_{1} 0.063, \mathrm{C}_{2} 0.063, \mathrm{C}_{3}-0.164, \mathrm{C}_{4}-0.072, \mathrm{C}_{5}-0.095, \mathrm{C}_{6}-0.169, \mathrm{O}_{7}-0.208, \mathrm{O}_{8}-0.166, \\
\mathrm{C}_{9} 0.047, \mathrm{C}_{10}-0.017, \mathrm{C}_{11}-0.143, \mathrm{C}_{12}-0.170 .\end{array}$ \\
\hline & \multirow[t]{2}{*}{ Intermediate } & AM1 & $\begin{array}{c}\mathrm{C}_{1} 0.054, \mathrm{C}_{2} 0.058, \mathrm{C}_{3}-0.170, \mathrm{C}_{4}-0.067, \mathrm{C}_{5}-0.124, \mathrm{C}_{6}-0.185, \mathrm{O}_{7}-0.230, \mathrm{O}_{8}-0.187, \\
\mathrm{C}_{9} 0.079, \mathrm{C}_{10}-0.096, \mathrm{C}_{11}-0.156, \mathrm{C}_{12}-0.224\end{array}$ \\
\hline & & PM3 & $\begin{array}{c}\mathrm{C}_{1} 0.065, \mathrm{C}_{2} 0.058, \mathrm{C}_{3}-0.147, \mathrm{C}_{4}-0.078, \mathrm{C}_{5}-0.095, \mathrm{C}_{6}-0.169, \mathrm{O}_{7}-0.208, \mathrm{O}_{8}-0.166 \\
\mathrm{C}_{9} 0.047, \mathrm{C}_{10}-0.019, \mathrm{C}_{11}-0.134, \mathrm{C}_{12}-0.168 .\end{array}$ \\
\hline \multirow{2}{*}{ Eugenyl acetate } & \multirow{2}{*}{ Transition } & AM1 & $\begin{array}{c}\mathrm{C}_{1} 0.057, \mathrm{C}_{2} 0.079, \mathrm{C}_{3}-0.197, \mathrm{C}_{4}-0.043, \mathrm{C}_{5}-0.136, \mathrm{C}_{6}-0.168, \mathrm{O}_{7}-0.190, \mathrm{C}_{8} \text { 0.306, } \\
\mathrm{O}_{9}-0.291, \mathrm{C}_{10}-0.253, \mathrm{O}_{11}-0.178, \mathrm{C}_{12}-0.081, \mathrm{C}_{13}-0.098, \mathrm{C}_{14}-0.157, \mathrm{C}_{15}-0.226 \mathrm{.}\end{array}$ \\
\hline & & PM3 & $\begin{array}{c}\mathrm{C}_{1} 0.042, \mathrm{C}_{2} 0.081, \mathrm{C}_{3}-0.174, \mathrm{C}_{4}-0.054, \mathrm{C}_{5}-0.113, \mathrm{C}_{6}-0.161, \mathrm{O}_{7}-0.156, \mathrm{C}_{8} 0.351 \\
\mathrm{O}_{9}-0.327, \mathrm{C}_{10}-0.139, \mathrm{O}_{11}-0.160, \mathrm{C}_{12} 0.046, \mathrm{C}_{13}-0.020, \mathrm{C}_{14}-0.145, \mathrm{C}_{15}-0.166 .\end{array}$ \\
\hline
\end{tabular}

distributed along the aromatic cycle site (Figure 4, Table 2). This clearly shows the high reactivity of eugenol compared to its corresponding acetate. This reactivity is due to mobility of hydrogen and the nucleophilicity on the aromatic ring.

From calculating wave functions, we observe that the charge distributions are mainly located on electrowithdrawing oxygen atoms in each molecule. They also are situated on aromatic ring and the strand allyl. The charge density is much higher under AM1 than under PM3. So, these results are in accordance with their energy properties (see Table 1) and the electronic properties of each substituent. The acetate group is an electron withdrawing type which reduces the aromatic cycle charge while hydroxyl group is an electron donor type that can provide its charge to the aromatic ring and thus increases its nucleophilic effect (Table 2).

\section{Conclusion}

In the present work, we have studied the conformational structure of eugenol and eugenyl acetate under torsional angle effect by performing semiempirical calculations using AM1 and PM3 methods. From quantum calculations, we have evaluated the strain energy of conformational interconversion. To provide a better estimate of stable conformations, we have plotted the strain energy versus dihedral angle. So, 
we have determined five geometries of eugenol (three energy minima and two transition states) and three geometries of eugenyl acetate (two energy minima and one transition state). We have verified the presence of the intermediate form of eugenol which corresponds to the trans form $\left(\mathrm{C}\right.$ or $\left.\mathrm{C}^{\prime}\right)$.

From the molecular orbital calculations, we deduce that the optimized trans form by AM1 method is more reactive than under PM3 method. We note that the charge distributions are mainly located on the aromatic ring and the strand allyl in each molecule. We can conclude that both methods are efficient. The AM1 method allows us to determine the reactivity and PM3 method to verify the stability.

\section{Conflict of Interests}

The author declares that there is no conflict of interest regarding the publication of this paper.

\section{References}

[1] E. Reverchon, "Supercritical fluid extraction and fractionation of essential oils and related products," The Journal of Supercritical Fluids, vol. 10, no. 1, pp. 1-37, 1997.

[2] W. Guan, S. Li, R. Yan, S. Tang, and C. Quan, "Comparison of essential oils of clove buds extracted with supercritical carbon dioxide and other three traditional extraction methods," Food Chemistry, vol. 101, no. 4, pp. 1558-1564, 2007.

[3] M. N. I. Bhuiyan, J. Begum, N. C. Nandi, and F. Akter, "Constituents of the essential oil from leaves and buds of clove (Syzygium caryophyllatum (L.) Alston)," African Journal of Plant Science, vol. 4, pp. 451-454, 2010.

[4] S. M. Palacios, A. Bertoni, Y. Rossi, R. Santander, and A. Urzúa, "Efficacy of essential oils from edible plants as insecticides against the house fly, Musca domestica L," Molecules, vol. 14, no. 5, pp. 1938-1947, 2009.

[5] M. H. Alma, M. Ertaş, S. Nitz, and H. Kollmannsberger, "Chemical composition and content of essential oil from the bud of cultivated Turkish clove (Syzygium aromaticum L.)," BioResources, vol. 2, no. 2, pp. 265-269, 2007.

[6] A. K. Srivastava, S. K. Srivastava, and K. V. Syamsundar, "Bud and leaf essential oil composition of Syzygium aromaticum from India and Madagascar," Flavour and Fragrance Journal, vol. 20, no. 1, pp. 51-53, 2005.

[7] K.-G. Lee and T. Shibamoto, "Antioxidant property of aroma extract isolated from clove buds [Syzygium aromaticum (L.) Merr. et Perry]," Food Chemistry, vol. 74, no. 4, pp. 443-448, 2001.

[8] A. A. Clifford, A. Basile, and S. H. R. Al-Saidi, "A comparison of the extraction of clove buds with supercritical carbon dioxide and superheated water," Fresenius' Journal of Analytical Chemistry, vol. 364, no. 7, pp. 635-637, 1999.

[9] G. Della Porta, R. Taddeo, E. D’Urso, and E. Reverchon, “Isolation of clove bud and star anise essential oil by supercritical $\mathrm{CO}_{2}$ extraction," LWT-Food Science and Technology, vol. 31, no. 5, pp. 454-460, 1998.

[10] F. N. Lugemwa, "Extraction of betulin, trimyristin, eugenol and carnosic acid using water-organic solvent mixtures," Molecules, vol. 17, no. 8, pp. 9274-9282, 2012.

[11] B. Jayawardena and R. M. Smith, "Superheated water extraction of essential oils from Cinnamomum zeylanicum (L.)," Phytochemical Analysis, vol. 21, no. 5, pp. 470-472, 2010.
[12] S. Ghosh, D. Chatterjee, S. Das, and P. Bhattacharjee, "Supercritical carbon dioxide extraction of eugenol-rich fraction from Ocimum sanctum Linn and a comparative evaluation with other extraction techniques: process optimization and phytochemical characterization," Industrial Crops and Products, vol. 47, pp. 78-85, 2013.

[13] S. Ghosh, D. Roy, D. Chatterjee, P. Bhattacharjee, and S. Das, "SFE as a superior technique for extraction of eugenol-rich fraction from Cinnamomum tamala Nees (Bay Leaf)-process analysis and phytochemical characterization," International Journal of Biological, Life Science and Engineering, vol. 8, no. 1, pp. 9-17, 2014.

[14] F. Memmou and R. Mahboub, "Composition of essential oil from fresh flower of clove," Journal of Scientific Research in Pharmacy, vol. 1, pp. 33-35, 2012.

[15] M. He, M. Du, M. Fan, and Z. Bian, "In vitro activity of eugenol against Candida albicans biofilms," Mycopathologia, vol. 163, no. 3, pp. 137-143, 2007.

[16] S. A. Guenette, F. Beaudry, J. F. Marier, and P. Vachon, "Pharmacokinetics and anesthetic activity of eugenol in male Sprague-Dawley rats," Journal of Veterinary Pharmacology and Therapeutics, vol. 29, no. 4, pp. 265-270, 2006.

[17] G. Blank, A. A. Adejumo, and J. Zawistowski, "Eugenol induced changes in the fatty acid content two Lactobacillus species," Lebensmittel-Wissenschaft. Technology, vol. 24, pp. 231-235, 1991.

[18] A. L. Dos Santos, G. O. Chierice, K. Alexander, and A. Riga, "Crystal structure determination for eugenyl acetate," Journal of Chemical Crystallography, vol. 39, no. 9, pp. 655-661, 2009.

[19] A. L. Dos Santos, G. O. Chierice, A. T. Riga, K. Alexander, and E. Matthews, "Thermal behavior and structural properites of plant-derived eugenyl acetate," Journal of Thermal Analysis and Calorimetry, vol. 97, no. 1, pp. 329-332, 2009.

[20] D. W. Marquardt, "An algorithm for least-squares estimation of nonlinear parameters," vol. 11, pp. 431-441, 1963. 

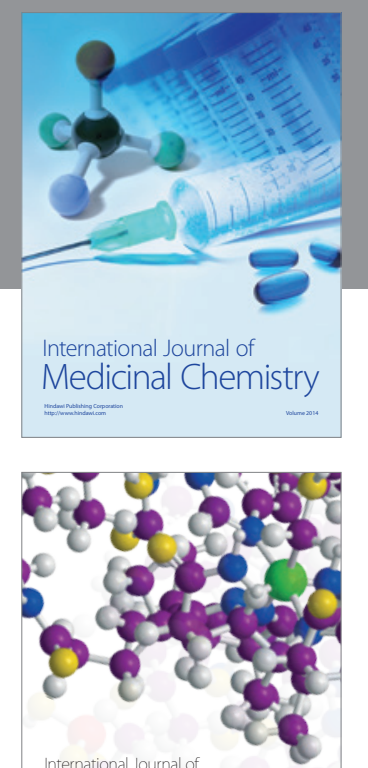

\section{Carbohydrate} Chemistry

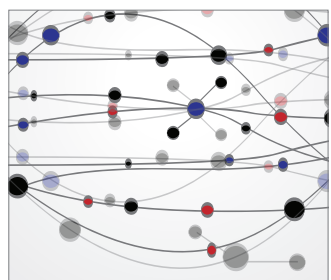

The Scientific World Journal
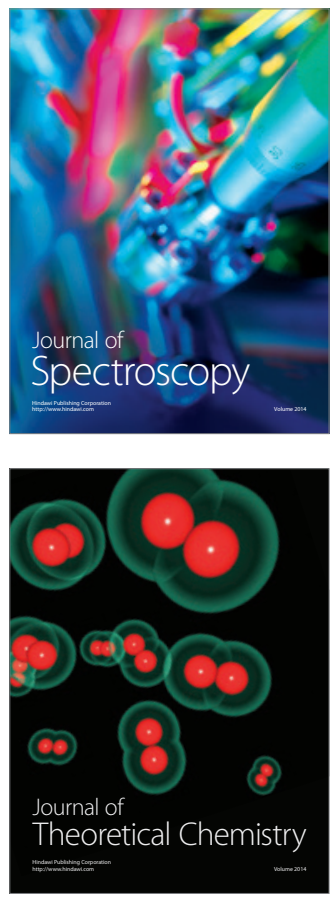
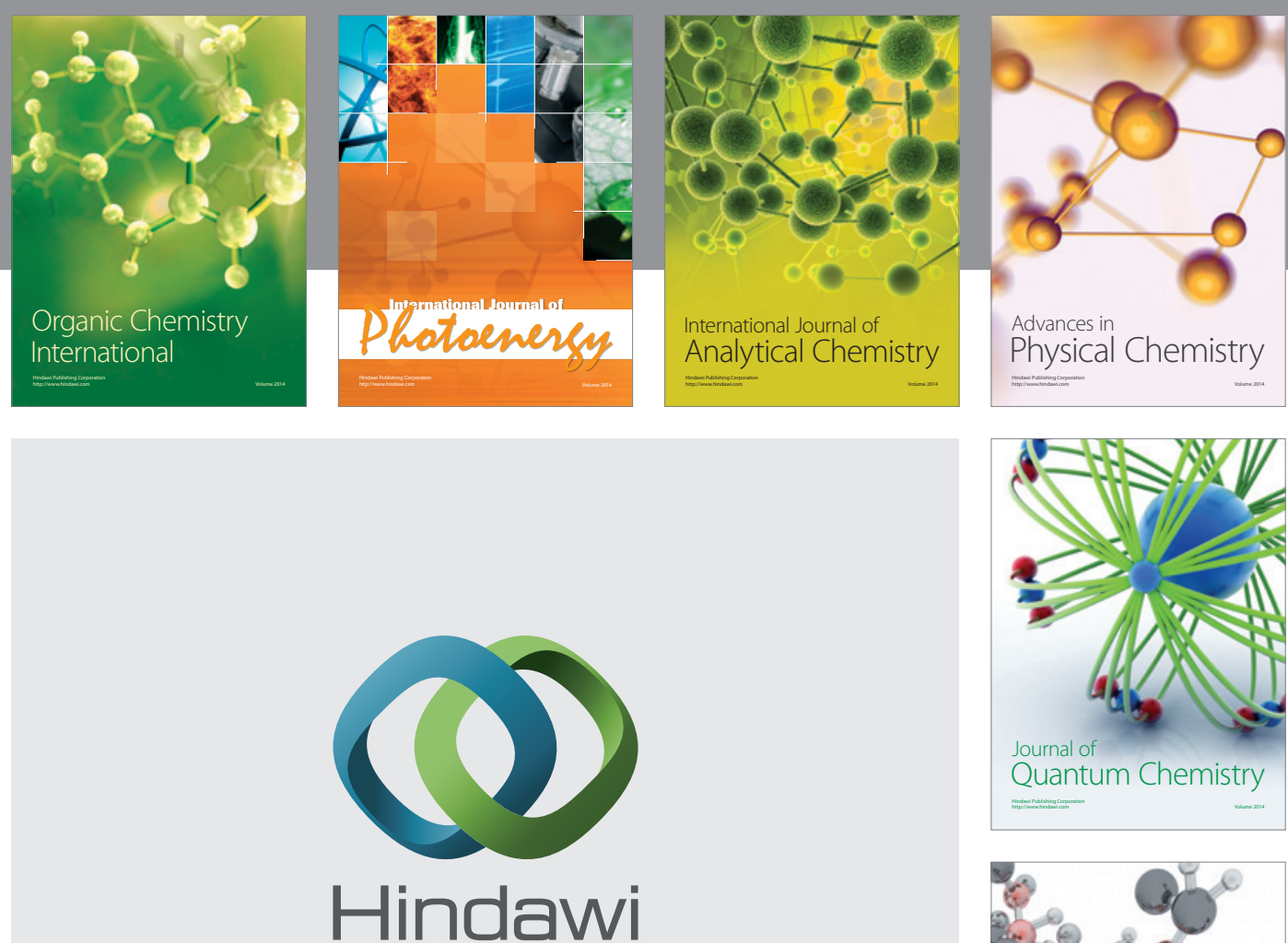

Submit your manuscripts at

http://www.hindawi.com

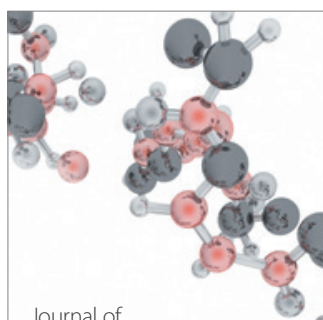

Analytical Methods

in Chemistry

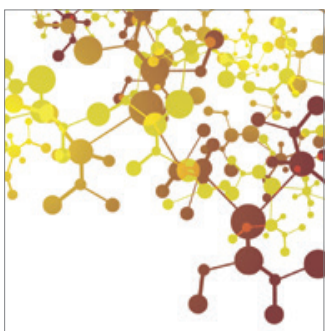

Journal of

Applied Chemistry

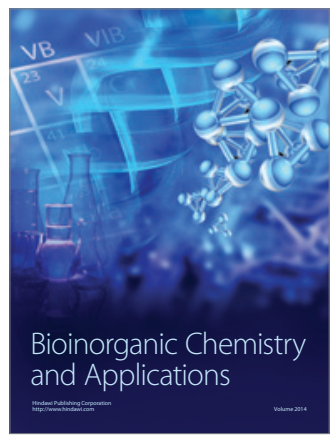

Inorganic Chemistry
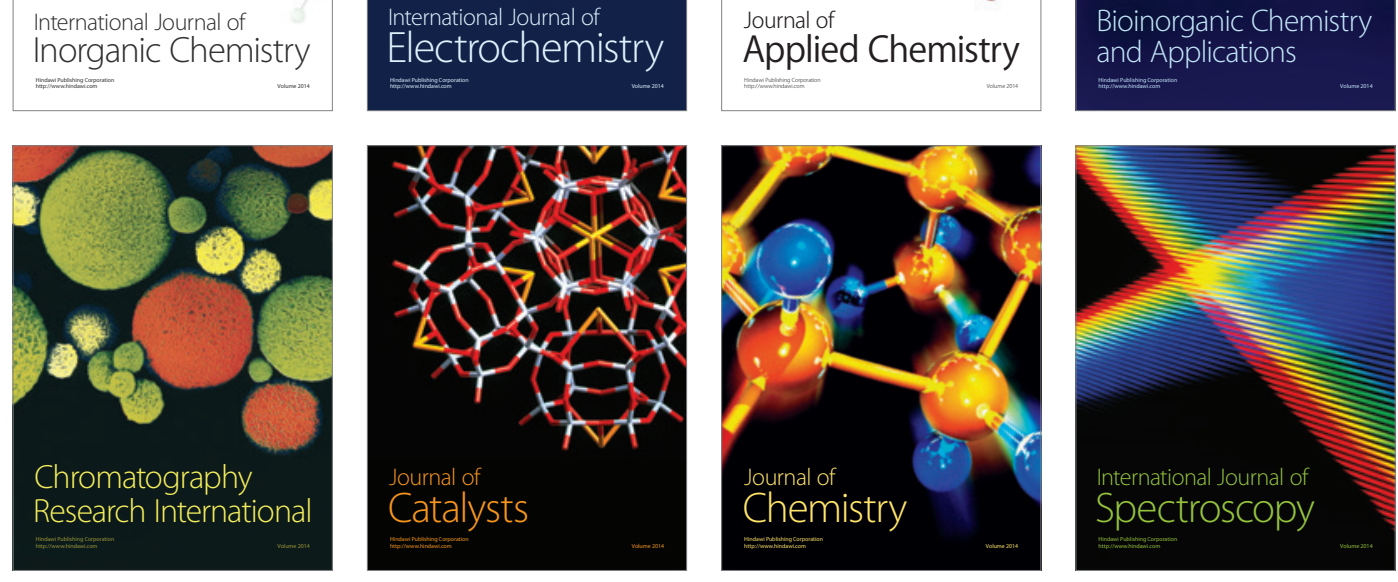